\title{
International Archives of Clinical Pharmacology
}

Case Report: Open Access

\section{Unacceptable Intravenous Administration of Chloral Hydrate Oral Solution}

\author{
Turgay Çokyaman ${ }^{1 *}$, Ömer Ertuğrul' ${ }^{2}$, Haydar Ali Taşdemir' and Ayhan Dağdemir ${ }^{2}$ \\ ${ }^{1}$ Department of Pediatrics, Division of Pediatric Neurology, Ondokuzmayıs University, Turkey \\ ${ }^{2}$ Department of Pediatrics, Division of Pediatric Hematology, Ondokuzmayıs University, Turkey
}

${ }^{*}$ Corresponding author: Turgay Çokyaman, MD, Fellow in Pediatric Neurology, Department of Pediatrics, Division of Pediatric Neurology, Ondokuz Mayıs University Medical Faculty, Kurupelit, Atakum 55139, Samsun, Turkey, Tel: +90-362-312-19-19, Fax:+90-362-457-60-91, E-mail: wolf6079@hotmail.com

\begin{abstract}
Chloral hydrate is very frequently used in medical procedures with the purpose of sedation. After oral or rectal administration, central nervous system (CNS) and respiratory depression, cardiac arrhythmia and gastric irritation are known as classical adverse effects. Although the adverse effects developing after enteral usage are well known, there are limited data in literature about the misuse of chloral hydrate oral solution intravenously and the adverse effects that may be seen after this usage. In this article, it is intended that chloral hydrate oral solution has been mistakenly administered intravenously and it is a fact that there isn't any seen complication except localized skin erythema.
\end{abstract}

\section{Keywords}

Chloral hydrate, Adverse effect, Pediatric sedation

\section{Introduction}

Chloral hydrate has been used in diagnostic procedures with the purpose of sedation since 1932 especially in pediatric medicine and dentistry due to its minimal effects on respiration [1]. It is a drug that has crystal structure, is resolved in water easily and applicate orally or rectally. Although the adverse effects developing after enteral usage are well known, there are limited data in literature about the misuse of chloral hydrate oral solution intravenously (IV) and the adverse effects that may be seen after this usage [2].

Sing et al. had reported that no other side effects than central nervous system (CNS) depression were observed in the two patients in whom chloral hydrate oral solution was misused intravenously (one with standard dose, and one with high dose) [3]. The present case is a third case in addition to the other two cases of misuse of chloral hydrate oral solution intravenously. Within the effective and safe dose range, $50 \mathrm{mg} / \mathrm{kg} /$ dose was erroneously administered via IV route. This case is presented since no other side effects such as CNS depression or cardiotoxicity other than localized skin erythema were observed.

\section{Case}

Electroencephalography (EEG) was planned to a one year old girl who was admitted with seizure complaint; however, this girl had not any health problem formerly and her physical and neurological examination was normal. Sleep EEG was not to be provided in following sleeplessness. Therefore, giving $50 \mathrm{mg} / \mathrm{kg}$ dose oral chloral hydrate to the patient who has $10 \mathrm{~kg}$ body weight was proposed. It was learned that after $500 \mathrm{mg}$ chloral hydrate had been dissolved with $5 \mathrm{cc}$ physiological saline, it had been misused intravenously in way of slow infusion instead of oral way. Shortly after this misadministration, the patient was closely observed in terms of phlebitis, central nervous system and respiratory depression, cardiac arrhythmia and hepatotoxicity. After intravenous use in the area of upper extremity, there wasn't any problem except the local skin erythema that was emerged in a few minutes later and recovered by itself. There wasn't any occurred organ dysfunction through 24 hour close observation, too.

\section{Discussion}

Effective and safe dose interval of chloral hydrate is $25-50 \mathrm{mg} / \mathrm{kg}$ [1]. It is confidently administered orally or rectally, adverse effects such as CNS and respiratory depression, cardiac arrhythmia and gastric irritation may be seen; however, hypothermia, hypotension, mycosis, vomiting, are flexia and flaccid paralysis is rarely occurred. The toxic dose of oral chloral hydrate in adults is about $10 \mathrm{~g}$, however cases were reported in which patients survived doses as high as $30 \mathrm{~g}$ [4]. A study conducted in 1992 published about 600 cases of chloral hydrate intoxication, and reported only 4 cases of death [5].

Major active metabolite of chloral hydrate is trichloroethanol and whereas half-life period in adults is 8 hours, this range can be reached to 40 hours in children due to slow metabolization of children. It is bounded to plasma proteins in range of $70-80 \%$ and is dispensed to all tissues including cerebrospinal fluid. If any adverse effect emerges after enteral usage as well as general support-reinforcing and symptomatic treatment, hemodialysis and peritoneum dialysis are proposed to increase elimination of trichlorethanol in necessary cases in case of intoxication $[6,7]$.

Since misuse of chloral hydrate oral solution intravenously is unusual, it is difficult to predict side effects that may occur. Most importantly, due to the agent's crystal structure and since the

Citation: Çokyaman T, Ertuğrul Ö, Taşdemir HA, Dağdemir A (2016) Unacceptable Intravenous Administration of Chloral Hydrate Oral Solution. Int Arch Clin Pharmacol 2:006 
Table 1: Clinical characteristics of the 3 patients to whom chloral hydrate oral solution was administered via IV route.

\begin{tabular}{|l|c|c|c|c|c|}
\hline & age & IV chloral hydrate dose & cardiotoxicity & CNS depression & \\
\hline & & & respiratory depression & skin lesion \\
\hline case 1 (Sing et al.) & 3 years & $39 \mathrm{mg} / \mathrm{kg}$ & no & yes/short-time lethargy \\
\hline & & & & \\
\hline case 2 (Sing et al.) & 15 months & $88 \mathrm{mg} / \mathrm{kg}$ & no & yes/short-time lethargy \\
\hline & & & no & yes \\
\hline case 3 (Cokyaman et al.) & 1 years & $50 \mathrm{mg} / \mathrm{kg}$ & no & no \\
\hline
\end{tabular}

required sterility conditions cannot be met during IV administration, this will pose risks of cutaneous or subcutaneous localized necrosis, and phlebitis in the vein into which the agent is administered. Moreover, rapid and high-dose IV administration may cause serious cardiac arrhythmias because of its proarrhythmic properties [8]. No cardiotoxic side effects were reported in the cases, including our case and the previous 2 cases (one was administered $88 \mathrm{mg} / \mathrm{kg} /$ high-dose IV chloral hydrate), but short-term CNS depression was mentioned in these 2 cases.

Toxication data relating to erroneous IV administration of chloral hydrate oral solution instead of enteral route in childhood are reported in only 2 studies in the literature. Especially, one of these cases to whom $88 \mathrm{mg} / \mathrm{kg}$ was given erroneously via IV route, which is above the oral effective and safe dose range (i.e $25-50 \mathrm{mg} /$ $\mathrm{kg}$ ) developed lethargy and required short-term ventilatory support with ambu bag. This patient who had no cardiotoxicity or another organ dysfunction, was discharged after being followed-up for two days. On the other hand, no serious side effects other than localized skin redness, similarly to our case, were observed in the other case to whom $39 \mathrm{mg} / \mathrm{kg} /$ dose was erroneously administered via IV route [3]. Brief information about our patient as well as 2 pediatric patients to whom the agent had been erroneously administered via IV route is shown in table 1.

In our case, except the local redness in the area of application, any adverse effect such as CNS and respiratory depression, cardiac arrhythmia, hepatotoxicity had not been observed. This condition make us think that the drug is given in safe dose range and possible adverse effects may be related with the dose of drug. It is thought that this adverse effect occurred following the misuse of chloral hydrate oral solution intravenously may be related with amount of dose rather than the route of administration.

\section{Author Contributions}

TÇ drafted the manuscript. TÇ and ÖE were involved in patient care and routine clinical follow up. HAT was involved in editing the manuscript. HAT and AD made helpful suggestions regarding the manuscript and made patient referrals.

\section{Conflict of Interest}

The authors declare that there are no conflicts of interest.

\section{Study Funding}

No study funding reported.

\section{Ethical Approval}

Informed consent was taken from the parents for publication.

\section{References}

1. Baselt RC (2004) Disposition of Toxic Drugs and Chemicals in Man. ( $7^{\text {th }}$ edn) 187-190.

2. Braham RL, Bogetz MS, Kimura M (1993) Pharmacologic patient management in pediatric dentistry: an update. ASDC J Dent Child 60: 270-280.

3. Sing K, Erickson T, Amitai Y, Hryhorczuk D (1996) Chloral hydrate toxicity from oral and intravenous administration. J Toxicol Clin Toxicol 34: 101-106.

4. Rall TW (1990) Chloral derivaties. In: Goodman \& Gilman's: The Pharmacological Basis of Therapeutics. 8th edition. Gilman AG, Rall TW Nies AS, Taylor P, eds. Pergamon Press, Elmsford, New York, 364-365.

5. Litovitz TL, Holm KC, Clancy C, Schmitz BF, Clark LR, et al. (1993) 1992 Annual report of the American Association of Poison Control Centers Toxic Exposure Surveillance System. Am J Emerg Med 11: 494-555.

6. Merdink JL, Robison LM, Stevens DK, Hu M, Parker JC, et al. (2008) Kinetics of chloral hydrate and its metabolites in male human volunteers. Toxicology 245: 130-140.

7. Buur T, Larsson R, Norlander B (1988) Pharmacokinetics of chloral hydrate poisoning treated with hemodialysis and hemoperfusion. Acta Med Scand 223: $269-274$.

8. Dogan-Duyar S, Willemse JL, Van hee P, Duval EL, Neels H (2010) Chloral hydrate intoxication in a 3-month-old child: Avoidance of hemodialysis by an immediate determination of trichloroethanol. Clin Biochem 43: 328-330. 